\title{
Brasil Adere ao Tratado da Antártida.
}

\author{
João Grandino Rodas \\ Professor Iivre-Docente de Direito Internacional \\ na Faculdade de Direlto da Unlversidade de \\ são Paulo.
}

A 16 de maio de 1975, o Brasil aderiu ao Tratado da Antártida, concluido em Washington, a $1 .^{\circ}$ de dezembro de 1959. Tal adesão torna a problemática relativa a essa região, de alto interesse para todos nós. ${ }^{1}$.

A Antártida é o sexto continente, com superfície constituída de terra recoberta de gelo, medindo cerca de 14 milhões de quilômetros quadrados, o que equivale à Europa e aos Estados Unidos reunidos. ${ }^{2}$ Dista dos outros continentes de 3.600 a 700 quilômetros. A hostilidade climática o torna inabitábel quase todo o ano, impossibilitando, assim, uma ocupação normal.

Razões econômicas, científicas, militares e estratégicas estão na raiz do interesse que os Estados demonstram por essa região. Acredita-se na existência de carvão, cobre, ferro, estanho, chumbo, manganês, ouro, prata, urânio e até mesmo de petróleo, embora seja discutível a possibilidade de

1. Tal tratado fol aprovado pelo Decreto Legislativo n. 56 , de 26 de Junho de 1975, promulgado pelo Decreto n.0 75.963, de 11 de Junho de 1975 e publicado no Diário Oficial da Uniáo de 14 de julho do mesmo ano. O fasciculo número 817 da Coleção de Atos Internacionais, publicada pelo Ministério das Relaçбes Exteriores, através da Divisáo de Atos Internacionais, estampa o tratado em questăo no original Inglês, com tradução portuguesa.

2. A regiáo ártica, que com a Antártida compóe as regiōes polares, possul estrutura geologica diversa, é uma massa de água gelada. 
exploração a níveis econômicos compensatórios ${ }^{3}$ Isso sem falar nas riquezas alimentares do Oceano Antártico. $\mathrm{O}$ controle da Antártida significa a dominação das rotas marítimas e aéreas do hemisfério austral, incluindo a ligação entre o Atlântico e o Pacífico. Descoberta em fins do Século Dezesseis, a Antártida vem a partir daí sendo explorada parcialmente.

Relativamente ao Direito Internacional, a Antártida suscita problemas de soberania territorial.

Em substituição ao princípio da ocupação efetiva de difícil aplicação devido às peculiaridades, tem sido aventados outros critérios, como o título derivado da descoberta, explorações científicas, controle civil ou administrativo - ocupação de apenas certos pontos do território -, teoria da contigüidade e teoria dos quadrantes.

O princípio da descoberta foi invocado por diversos Estados. Entre 1739 e 1840, a França, o utilizou com referência às ilhas Bouvet, Grozet, Marion, ao arquipélago Kergulém e à Terra Adélia ${ }^{4}$ A Inglaterra e a Noruega fizeram o mesmo, a primeira em 1883, relativamente às ilhas Falklands ou Malvinas, e a segunda com relação à região conhecida como Rainha Maud ${ }^{5}$

A Inglaterra já acenou as setenta e cinco expedições realizadas na Antártida antes da Segunda Guerra Mundial, como fundamento às suas pretensões. A União das Repúblicas Socialistas Soviéticas teve comportamento idêntico, com base

3. Goox, entretanto, acredita que "the major exports of Antartica are scientific data ... and these data may turn out to be of vastly more value to all mankind than all the mineral riches of the continent and the life of the seas that surround it". Citado por Mouton, M.W. - The International Regime of the Polar Regions in Recuell des Cours de l'Academie de Droit International, 1962, v. 107, p. 227.

4. DoLLot, René, Le Droit International des Espaces Polaires in Recueil des Cours de l'Academte de Drolt International de la Haye, 1949, v. II, p. 177-179.

5. V. Doliot, René, Op. cit., p. 179-182. 
em uma expedição realizada em 1820. A Argentina, por seu turno, invocou suas freqüentes explorações e a manutenção de uma estação metereológica permanente nas Ilhas Orcades do Sul, a partir de 1904. Esse país sustenta ter sido essa a primeira ocupação efetiva do território antártico. Em 1908 esse arquipélago foi anexado pela Inglaterra.

A idéia de vizinhança, continuidade ou contigüidade, baseada na analogia de estrutura geológica, embora de difícil admissão relativamente à Antártida, foi alegada pela Argentina como justificação de seus direitos soberanos, unilateralmente declarados através dos decretos de 15 de julho de 1939 e 9 de outubro de 1946.

Fauchille imaginou a divisão da Antártida em quatro quadrantes $^{6}$ : o sul-americano, o pacífico, o australiano e o africano, sendo cada um deles administrado conjuntamente pelos Estados dos referidos continentes ?.

Para o chileno Pinochet de la Barra, que retomou essa teoria em 1944, cada Estado teria um setor de extensão proporcional ao valor de seus títulos antárticos.

As pretensões chilenas foram formuladas pela primeira vez, em 1909, por ocasião do nono Congresso Internacional de Geografia, realizado em Genebra. Contudo, somente a 6 de novembro de 1940, através de decreto, o Chile passou a considerar como seu território uma vasta região, a Antártida chilena ${ }^{8}$.

Na competição pela Soberania sobre parcelas do território da Antártida entraram a Inglaterra, a França, a Noruega, círculo.

6. Quadrante significa em geometria a quarta parte da circunferência do

7. Fauchilde, Paul - Traité de Droit International Public. Paris, Librairie Arthur Rousseau, 1925, Tomo I, 2. ${ }^{2}$ parte, p. 651-663.

8. V. DoLlot, René, Op. cit., p. 183. 
a Austrália, a Nova Zelândia, o Chile e a Argentina ${ }^{9}$. Os cinco primeiros países reconheceram mutuamente suas possessões, originadas de atos unilaterais, que constituem setores triangulares, tendo o polo por centro. Embora tais países não se tenham entitulado a toda Antártida, deixando de reivindicar importante zona entre os setores da Nova Zelândia e Inglaterra, parte das zonas pretendidas pelo Chile e pela Argentina ${ }^{10}$ se superpõe ao setor britânico. A 4 de maio de 1955 , a Inglaterra submeteu essa disputa à Corte Internacional de Justiça que, acolhendo a argumentação do Chile e da Argeñtina, julgou-se incompetente, em 16 de março do ano seguinte ${ }^{11}$.

Embora os Estados Unidos houvessem realizado durante o século passado e o atual, várias expedições à Antártida nunca afirmaram sua soberania sobre qualquer porção desse continente ${ }^{12} \mathrm{Em}$ contrapartida jamais reconheceram as pretensões dos outros países, considerando-o aberto apenas à pesquisa científica. Isso se depreende das declarações oficiais de 13 de maio de 1924, 27 de dezembro de 1946, 9 de abril de 1947 e 9 de agosto de 1948.

A União das Repúblicas Socialistas Soviéticas também تealizou expedições ${ }^{13}$, não reivindicando, contudo, parcela territorial. Através de nota ao governo norueguês, de 27 de janeiro de 1939 e do Memorando de 7 de junho de 1950, dirigido aos Estados Unidos e aos países componentes do clu-

9. Pelo artigo 2.0, letra $e$ do Tratado de Paz de Săo Francisco, datado de 8 de setembro de 1951, o Japāo renunciou "a toda relvindicaçāo de direltos, títulos ou interesses relacionados com qualquer parte da área, decorrentes de atividades de nacionais Japoneses ou de quaisquer outras fontes". Tm 1911, 0 Japão enviara à Antártida a expedição de Shizaré.

10. Respectivamente por decreto de 23 de fevereiro de 1948 e pela proclamação de 1.0 de agosto do mesmo ano.

11. CIJ Recueil, 1956, p. 12-17.

12. No século XIX, as mais importantes expediçóes norte americanas, 10ram as lideradas por Palmer e Wilker. Neste século foi a de Byrd.

13. Bellingshausen e Lazarev nas expediçóes de 1819 e 1921 circunnavegaram o continente, tendo descoberto a Terra Alexandre I e a Ilha Pedro I. Varonine chefiou uma expedição em 1946. Em 1957 uma expedição soviética arvorou o pavilhão russo no polo magnético. No ano seguinte o mesmo se deu na llha Zovodoski. 
be antártico, tal país afirmou não reconhecer qualquer decisão unilateral ou convencional de que não seja partícipe.

A primeira proposta para a internacionalização da Antártica foi feita pelos Estados Unidos, através de uma nota, datada de 28 de agosto de 1948. Em 1956, a India levou à consideração da Assembléia Geral da Organização das Nações Unidas um projeto tendente à neutralização da Antártica que não obteve êxito ${ }^{14}$.

São variadas as formas possíveis de internacionalização. A institucionalização supraestatal colocaria a Antártida sob a égide de uma organização especializada que seria competente para distribuir concessões. Tratar-se-ia de uma solução eminentemente técnica que afastaria a possibilidade de soberania estatal e teria naturalmente contra si a opinião dos Estados que se entitulam soberanos sobre setores da Antártida. Outra forma de internacionalização seria a tutela delegada, através da qual a Organização das Nações Unidas, concederia a administração do território a um ou vários de seus membros, à semelhança dos mandatos da Sociedade das Nações e dos territórios sob tutela da Organização das Nações Unidas. O condomínio, outra forma, estabeleceria a hegemonia sobre a Antártida por parte de pequeno número de Estados. A internacionalização proposta pelos Estados Unidos em 1948, consagrava esta hipótese. $\mathrm{O}$ controle da região ficaria com os Estados Unidos e com os sete países que se intitulavam soberanos de setores antárticos. A última forma seria a internacionalização contratual que resultaria de uma repartição convencional da Antártida com fundamento nos direitos e títulos existentes, e da subordinação desse continente a um estatuto estabelecido através de um tratado internacional, a ser aplicado pelos Estados ${ }^{15}$.

14. Fm 1958, o mesmo pais sugeriu que a XIII Assembléla da Organlzação das Naçóes Unidas adotasse um estatuto para a Antártida. Tal órgão não chegou a considerar o assunto.

15. V. DupUY, René Jean, Le Statut de l'Antarctique in Annuaire Françals de Droit International, 1958, p. 215-218. 
O Ano Geofísico Internacional ${ }^{16}$ abriria a possibilidade de internacionalizar de fato a Antártida, colocando em segundo plano a sua repartição apenas teórica e consequiente soberania nominal.

Não se deve subestimar, contudo, a importância da implantação soviética em regiōes antárticas, na decisão dos Estados Unidos de convocar uma convenção para estabelecer um regime internacional, mesmo que provisório.

Através de uma nota, de 2 de maio de 1958, o Departamento de Estado Americano dirigiu-se a onze Estados - aos sete componentes do clube antártico e a União das Repúblicas Socialistas Soviéticas, União Sul Africana, Bélgica ${ }^{17}$ e Japão - propondo um acordo que estabelecesse a liberdade da pesquisa científica na Antártida e a sua utilização unicamente para fins pacíficos. Com o intutito de facilitar a concordância, propôs apenas o congelamento e não a renúncia dos direitos históricos e reivindicaçōes de soberania ${ }^{18}$.

A partir de 13 de junho de 1958 , iniciou-se a reunião de um grupo de trabalho, constituído por representantes dos

16. O ano Geofísico Internacional realizou-se de $1 .^{\circ}$ de Julho de 1957 a 31 de dezembro de 1958 , tendo concentrado o trabalho de cerca de 60.000 cientistas de 67 nacionalidades, em 4.000 estaçóes científicas. A denominação original, Terceiro Ano Polar, foi mudada pela Assembléia Geral do Conselho Internacional das Associaçöes Cientificas, realizada em Amsterdan, em 1952 para que o âmbito dos estudos pudesse ser mais amplo. $O$ primeiro e o segundo Anos Polares foram realizados respectivamente em 1882-1883 e 1932-1933. A fím de manter - clima de cooperação cientifica, atingida pelo Ano Geofísico Internacional, relativamente à Antártida, fundou-se em Haia, em 1958, a Comissão Especial de Pesquisa na Antártica (ScAR)

17. A Bélgica, invocando as expediçóes de Guerlache levadas a efeito em 1898 e 1899, da mesma forma que o governo russo, considerava que nenhum regime poderia ser estabelecido na Antártica, sem seu consentimento. (V DUPUY, op. cit., p. 209).

18. Sugestóes houveram no sentido de resolver as pendências referentes à Antártida através de uma Conferência internacional à moda da Conferência de Berlim de 1844-1945, precedida, segundo Jessur, de uma resolução da Corte Internacional de Justiça. V. JEssur, Philip, Sovereignty in Antarctica in The American Journal of International Law, 1947, v. 41, p. 119 e Dollor, René, op. cit., p. 189-190. Sobre a proposta norte-americana, ver as consideraçōes de DUPUY, op. cit., p. 218-229. 
doze países interessados ${ }^{19}$, que preparou caminho para a realização da Conferência de Washington sobre a Antártida, de 15 de outrubro a 1.0 de dezembro de $1959 .{ }^{20} \mathrm{O}$ resultado foi a Convenção de Washington, também conhecida como tratado da Antártida, que foi assinado pelos citados países a $1 .^{\circ}$ de dezembro de 1959 , tendo entrado em vigor a 23 de junho de 1961. Posteriormente à assinatura aderiram ao tratado os seguintes países: Rumênia, Polônia, Checoslováquia, República Democrática Alemã, Holanda, Dinamarca e agora o Brasil.

O preâmbulo do tratado denota a aceitação da proposta americana, pois traz como objetivos a pacificação e a cooperação científica.

Para os fins do tratado, a Antártida é definida como sendo a região situada ao sul de sessenta graus de latitude sul, incluindo as plataformas de gelo (art. 6. ${ }^{\circ}{ }^{21}$. Tal definição exclui certas ilhas situadas entre quarenta e sete e sessenta graus de latitude sul, que constituem a fronteira geográfica mais aceitável para a Antártida.

19. O interesse da União Sul Africana pela Antártida deriva da noção de contiguidade e do fato de tal país exercer soberania sobre algumas ilhas situadas no Oceano Glacial.

20. As minutas dessa Conferêncla nunca chegaram a ser publicadas.

21. A zona de segurança continental, contra a qual qualquer ataque será considerado como um ataque contra todos os Estados americanos definida pelo art. 4. ${ }^{\circ}$ do Tratado Interamericano de Assistência Recíproca de 2 de setembro de 1947, ultrapassa os 60 graus de latitude sul. Logo existe uma zona coberta tanto pelo Tratado de Washington como pelo Tratado acima citado, trata-se da Antértida Americana, compreendida entre $24.0^{\circ}$ e $29 .^{\circ} \mathrm{W}$. No início da Conferência de Washington o delegado chileno Mors mostrou preocupação que o tratado a ser concluído pudesse enfraquecer a aplicação do tratado assinado no Rio de Janeiro a 2 de setembro de 1947. O único fruto da colocação do delegado chileno fol uma declaração conjunta dos governos norte-americano, argentino e chileno, por ocasiáo da assinatura do Tratado da Antártida: "The Governments of the United States of America, Argentina and Chile, on the occasion of the signing of the Antarctic Treaty, declare that the Antarctic Treaty does not affect treir obligations under the Inter-American Treaty of Reciprocal Assistance, signed at Rlo de Janeiro, Brazil, in 1947". Tal declaraçäo, como pondera HayToN, por não ser integrante do tratado "is of no legal consequence, and does not dissolve incompatibilities". (Citado por Mouton, op. cit., p. 268). 
Medidas de caráter militar como estabelecimento de bases, construção de fortificações, manobras e testes de armas (art. $1^{\circ}{ }^{\circ}$, bem como explosões nucleares e deposição de dejetos radioativos (art. 5..$^{\circ}$ ) ficam proibidas.

Instituiu-se a liberdade da pesquisa científica e a cooperação internacional, através do intercâmbio de informações relativas a programas científicos, de pessoal técnico e de observações e resultados científicos obtidos na Antártida (arts. 2. ${ }^{\circ}$ e $3^{\circ}$ ) . O tratado prevê a possibilidade de as partes designarem observadores, com acesso a todo momento a qualquer região da Antártida, para inspecionar estações, instalações, materiais, navios ou aeronaves. A inspeção aérea também é facultada às partes contratantes, a qualquer momento (art. $\left.7^{\circ}\right)^{22}$. Tanto os observadores como o pessoal científico enviado pelas partes contratantes ficam sujeitos durante a missão unicamente à jurisdição do Estado que os enviar (art..$^{\circ}$ ). Essa é uma particularidade interessante do tratado, pois representa uma concessão por parte dos países que se entitulam soberanos sobre regiões da Antártida. Tal condescendência levou Mouton a considerar que "From the jurisdictional point

22. O primeiro Estado signatário do Tratado a demonstrar intenção de realizar inspeçōes na Antártida foram os Estados Unidos em 1963. Fol a Nova Zelándia, contudo, a pioneira no envio de observadores que, de 29 de novembro a 9 de dezembro de 1963, inspecionaram as estaçōes norte-americanas de McMurdo, Polo Sul e Byrd.

Ainda em dezembro de 1963, dois observadores, um da Inglaterra e outro da Austrália, visitaram a estação neozelandesa denominada Scott, além dos três supra-citados.

Em Janeiro de 1964, dois grupos de observadores norte-americanos foram enviados à Antártida. O primeiro grupo inspecionou as bases argentinas. Decepción e Esperanza, as chllenas Gabriel Gonçalves Videla e Pedro Aguirre Cerda e as inglesas $B$ e $F$. $O$ segundo dirigiu-se para a estação scott, para duas estaçóes soviéticas Mirnyy e Vostok e para a base francesa Dumont D'Ưville.

Observadores argentinos inspecionaram em fevereiro de 1965, a estaçăo americana Palmer.

Os relatórios de todas as inspeçōes mencionadas sāo unânimes em afurmar que as atividades efetuadas nas várias estaçōes nāo violavam as cláu. sulas. (V. Smssarian, James Inspection Experience Under the Antarctic Treaty and the International Atomic Energy Agency in The American Journal of International Law, v. 60, n. 3, Julho de 1966, p. 506-507.) 
of view ... there is no territorial sovereignty, in other words Antarctica is "terra nullius" 23.

As disputas derivadas da interpretação e aplicação do tratado se não forem resolvidas consoante o artigo 33 da carta da Organização das Nações Unidas, isto é, através de negociação, inquérito, mediação, conciliação e arbitragem, poderão, mediante o assentimento de todas as partes, serem submetidas à Corte Internacional de Justiça (art. 11) ${ }^{24}$

$\mathrm{O}$ tratado não obstante esteja aberto à adesão de todo Estado membro da Organização das Nações Unidas ou outro Estado convidado, subordina tal adesão ao consentimento expresso de seus membros (art. 13). O caráter hermético do tratado aparece ainda mais claramente, na limitação dos representantes às reunióes previstas pelo art. $90^{\circ}$ e no procedimento de revisão (art. 12).

$\mathrm{O}$ artigo $90^{\circ}$ estabelece a realização de reuniões periódicas, de informação e consulta, destinadas ao estudo e formulação de recomendações que facilitem a realização dos objetivos do tratado. Para que tais recomendações se tornem efetivas, devem ser aprovados pelos governos de todas as partes contratantes, habilitadas a participar nas reuniões. Adotou-se, assim o critério da unanimidade, detendo, por conseguinte, cada parte contratante o direito de veto. $\mathrm{O}$ tratado contudo não criou um secretariado permanente.

São membros natos dessas reuniões os doze Estados signatários (art. $9 .^{\circ}, \S 1 .^{\circ}$ ), enquanto que os Estados que aderiram posteriormente só poderão delas participar "enquanto como parte contratante demonstrar seu interesse pela Antártida, conduzindo atividade substanciais de pesquisa científica, tais como o estabelecimento de uma estação científica ou o envio de expediçōes" (art. 9. $.^{\circ} \$ 2 .^{\circ}$ ).

23. Movton, op. cit., p. 262.

24. A cláusula de Jurisdição obrigatória da Corte Internacional de Justiça, propugnada pela Inglaterra e pelos Estados Unidos, não resistiu à obstinaçáo da Argentina e do Chile. 
A simples adesão ao tratado quase nada significa, pois não dará nem o direito de representação nas reuniões, nem o direito de ser ouvido em caso de emenda ao tratado (art. $\left.12, \S 10^{\circ}\right)$.

A sugestão americana de congelar o "status quo" jurídico, da Antártida foi incorporado ao tratado, através do artigo $4 .^{\circ}, \$ 1 .^{\circ}$, que estabelece que nenhuma disposição do tratado significa renúncia ou abandono total ou parcial dos direitos de soberania ou reivindicação territorial, afirmados anteriormente $^{25}$. Por outro lado, nenhum ato ou atividade realizada na vigência do tratado é suscetível de constituir fundamento para fazer valer, sustentar ou contestar reivindicação de soberania na Antártida (art. 4. $\left.{ }^{\circ}, \$ 2 .^{\circ}\right)^{26}$.

$\mathrm{O}$ artigo $12, \S 2 .^{\circ}$ prevê a possibilidade de após trinta anos a partir da entrada em vigor, ou seja, em 1991, qualquer Estado habilitado a participar nas reuniões previstas no artigo 9. ${ }^{\circ}$, convocar uma conferência de todas as partes contratantes para rever o funcionamento do tratado. Passados dois anos da convocação, sem que uma emenda tenha entrado em vigor, qualquer parte poderá retirar-se do tratado, sendo que tal retirada entrará em vigor somente dois anos após ter notificado o depositário nesse sentido. Logo a vigência do tratado irá pelo menos até 1993.

25. Dupoy descreve minuclosamente o estado das reivindicaçōes territorlais sobre territórios antárticos, às vésperas do Tratado de Washington em seu artigo Le statut de l'Antarctique, op. cit., p. 201-205.

26. O congelamento fol uma solução de compromisso, pols a corrente de internacionalização da Antártida, encabeçada no seio da Conferência pela União das Repúblicas Socialistas Soviéticas, sofreu firme oposição da Argentina e do Chile.

Hayton, seguido por PHLEger, considera que "The Treaty certainly purports to establish a regional regime binding even on on-members is found in the obligation (laid down in Artiche $\mathrm{X}$ )". Mouton, baseado na máxima "pacta tertiis nec nocent nec prosunt" năo aceita a interpretação de HAY'TON e acredita que, hipoteticamente, um terceiro Estado possa estabelecer-se em um setor livre da Antártida, fundamentando assim pretensỏes à soberania. (V. MouToN, Op. cit., p. 258-259). 
A decisão do Brasil em aderir ao tratado, tomada após longa maturação, leva-nos a crer que participará ativamente na pesquisa científica em regiōes antártidas. Como se depreende do exame do tratado, tal participação, na forma de envio de expedições científicas ou instalações de estações científicas, é necessária se nosso país desejar realmente participar do tratado da Antártida ${ }^{27}$. A adesão, portanto, é apenas o primeiro passo.

\section{Bibliografia .}

Cavart, Louís, Le Droit International Public Positif, Paris, Editions A. Pedone, 1969, Tomo II, p. 682-691.

DozLot, René, Le Droit International des Espaces Polaires, in Recuell des Cours de l'Academie de Drolt International de la Haye, 1949. V. 75, p. 114-194.

Dupuy, René Jean, Le Statut de l'Antarctique in Annuaire Français de Drolt International, 1958, p. 196-229.

Fauchine, Paul, Traité de Droit Internationol Public, Paris, Librairie Arthur Rousseau, 1925, Tomo I, 2.a parte.

Jessur, Phillp C., Sovereignty in Antarctica, in The American Journal of International Law, 1947, v. 41, p. 117-119.

LoNDero, Magdalena, O Direito Internacional das Regiōes Polares in Boletim da Sociedade Brasileira de Direlto Internacional", Ano XXIV, Janeiro-Dezembro 1968, n.os 47 e 48, p. $79 / 90$.

O'CoNner, D.P., International Law, Londres, Stevens \& Sons, v. I, p. 450-453.

Mouton, M.W., The International Regime of the Polar Regions, in Recuell des Cours de l'Academie de Droit International de la Haye, 1962, v. 107, p. 168-284.

SIMSARIAN, James, Inspection Experience Under the Antartic Treaty and the International Atomic Energy Agency, in The American Journal of International Law, Julho, 1966, v. 60, n. ${ }^{\circ} 3$, p. 502-510.

27. preciso na terminologia de Mouton que sejam "acceding and active Parties". Mouton, op. cit., p. 263. 